\title{
HEAVY METALS AND PHOSPHORUS FORMS MOBILIZATION DURING THE RE-SUSPENSION OF BOTTOM SEDIMENTS OF THE PRUT RIVER
}

\author{
Larisa Postolachi \\ Institute of Chemistry of Academy of Sciences of Moldova, 3, Academiei str., Chisinau MD-2028, Republic of Moldova \\ e-mail: larisapostolachi@gmail.com; phone: (+373 22) 7397 31; fax: (+373 22) 739954
}

\begin{abstract}
Bottom sediments of the river are repositories for various elements, acting both as sinks and sources of supplying of elements to overlying water horizon. Re-suspension of the bottom sediments of the Prut River was performed in field conditions by „aquarium" method. The results suggest that during the re-suspension, bottom sediments can become a relevant source of heavy metals and phosphorus forms which are mobilized in the water horizon overlying the bottom sediments.
\end{abstract}

Keywords: bottom sediments, re-suspension, the Prut River.

\section{Introduction}

Metals discharged into aquatic systems are mostly adsorbed on suspended particles and fine grained sediments [1]. Bottom sediments play the essential role in the processes of phosphorus transformation and its accumulation in aquatic systems $[2,3]$. Mobilization-immobilization processes on the surface of sediments occur through and/or participation of the interstitial water. During the desorption process from sediments, phosphorus compounds are accumulated in interstitial water and then can be mobilized in the water horizon overlying the bottom sediments [4]. Reverse process, the immobilization from water in sediments, also occurs through interstitial water. The direction of mobilizationimmobilization processes determines pollution - self-purification processes of water bodies [5].

Sediments are not passive collectors of heavy metals. Polluted sediments are periodically subjected to resuspension processes resulting from natural events (e.g. storms, strong waves) as well as from anthropogenic induced activities (e.g. dredging). The main part of the re-suspended material is initially in an anoxic state and will be re-oxidized more or less quickly in the oxic water column above sediments [6].

Mobilization/immobilization processes are better elucidated for marine waters (Fig. 1). The mobilization of heavy metals from sediments can be increased due to the following factors: (i) changing of redox conditions; (ii) lowering the $\mathrm{pH}$ and (iii) the presence of complexing agents, which can form soluble metal complexes [6,7]. Additionally, the mechanical perturbation (erosion, dredging, bioturbation) can also affect the metals mobilization.

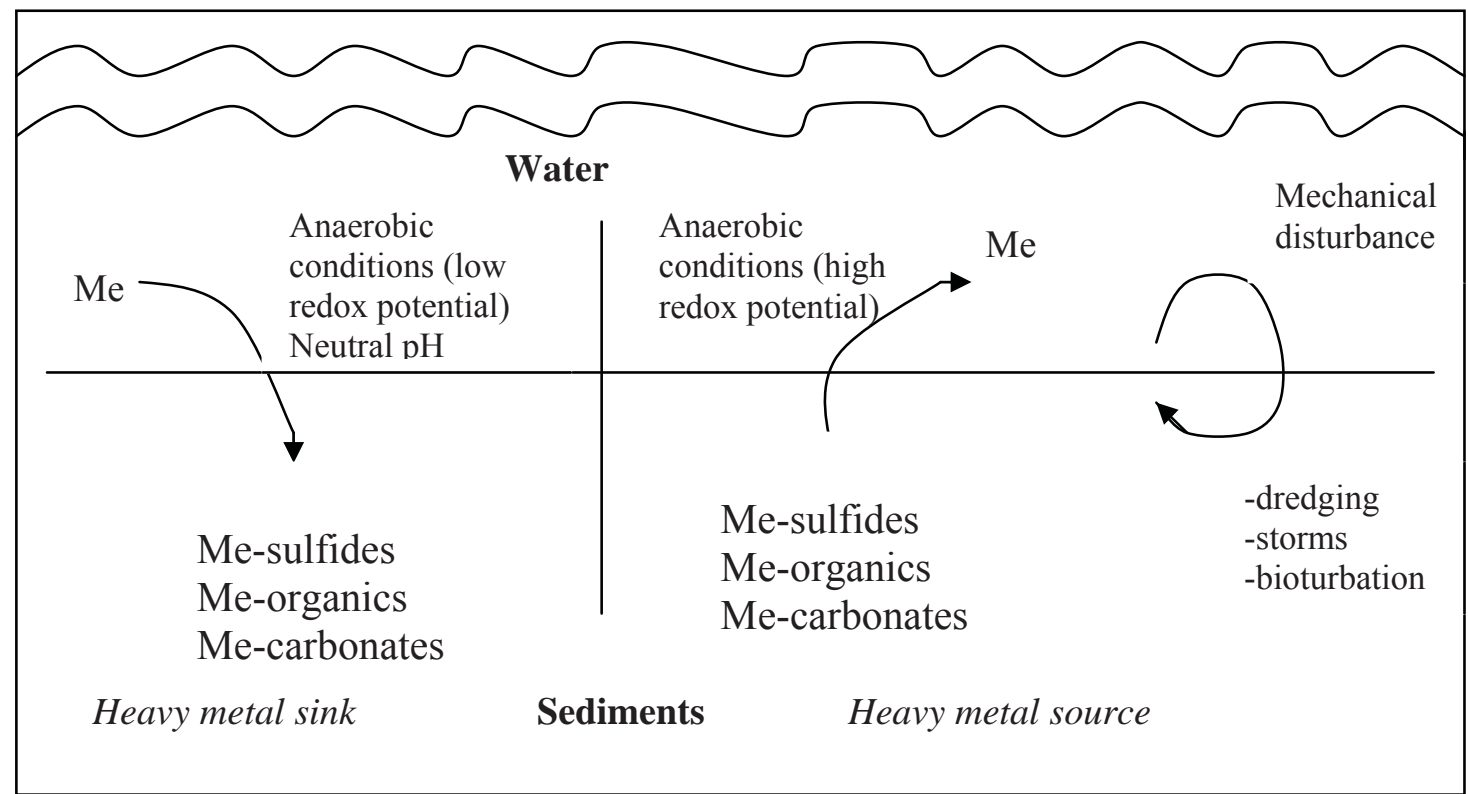

Figure 1. Sediments as a sink and a source of pollution by heavy metals (Me). Source: Stigliani W. [7]. 
The objectives of this paper were (i) to establish the desorbed amounts of heavy metals and phosphorus forms during the re-suspension of bottom sediments from the Prut River performed in field and laboratory conditions and (ii) to highlight the contribution of bottom sediments for surface water quality.

\section{Material and methods}

The re-suspension of bottom sediments of the Prut River was performed in field conditions by „aquarium” method - carefully mixing the sediments in a glass cylinder (without bottom, about $20 \mathrm{~cm}$ in diameter) implanted in the sediments at a depth of $5 \mathrm{~cm}$ [5]. To perform the sediments desorption, fresh (wet) samples were stirred with distilled water for 2 hours.

The content of heavy metals and phosphorus forms in the interstitial water of bottom sediments was determined after centrifugation of fresh (wet) sediments. After that interstitial water was filtered through membrane filters $(0.45$ $\mu \mathrm{m}$ pore diameter) and stored in the dark at $4^{\circ} \mathrm{C}$ until analysis. Heavy metal analyses were conducted using atomic absorption spectrometer AAS-3. The content of phosphorus forms (orthophosphates, condensed and organic phosphorus) was determined using World Health Organization recommendations [8].

\section{Results and discussion}

\section{Heavy metals mobilization during re-suspension of bottom sediments}

Mobilization/immobilization processes at the water-sediments interface is performed through direct participation of interstitial water [5]. As a rule, the content of heavy metals in the interstitial water of sediments is higher than in the water layer, which suggests that under dynamic conditions, i.e. during of re-suspension, the bottom sediments can become important sources of pollutants in the water column.

Figures 2 and 3 are presented the content of heavy metals $(\mathrm{Cu}, \mathrm{Zn}, \mathrm{Fe})$ in the water layer, before and after the re-suspension of bottom sediments (ReS).

The obtained results indicate that the re-suspension of sediments, carried out in the field conditions, causes the increase, in the water layer, of $\mathrm{Cu}$ content about 1.5 times, $\mathrm{Zn}$ of 1.8-5.7 times and Fe of 1.1-39 times, in comparison with data recorded until the re-suspension. In such conditions, the quantities of mobilized metals in the water layer are for $\mathrm{Cu}$ about $19-52 \%$, for $\mathrm{Zn} 23-100 \%$ and for $\mathrm{Fe} 7-32 \%$ of their content in the interstitial water of bottom sediments.

$\mathrm{Cu}$

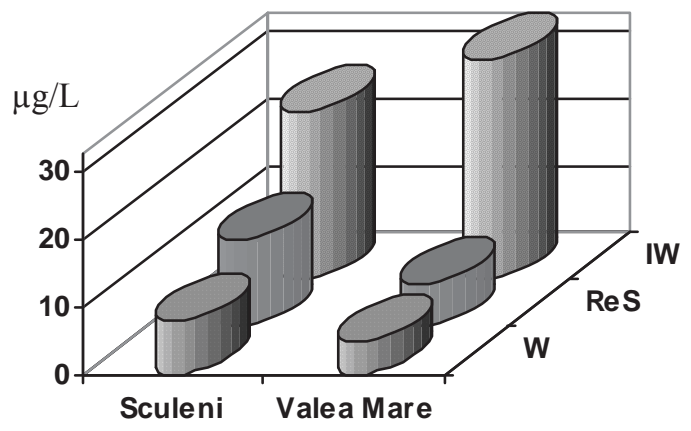

Zn

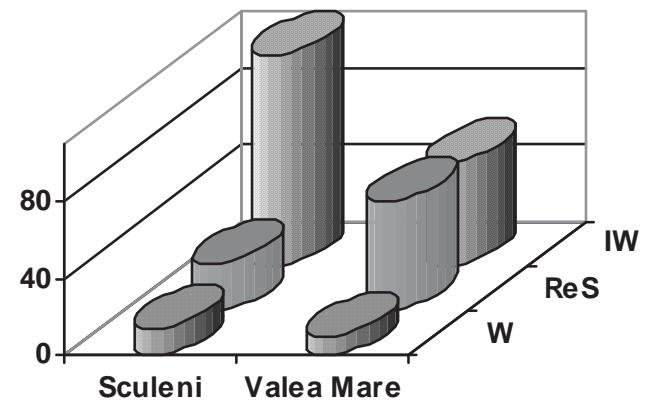

Figure 2. Dynamics of $\mathrm{Cu}$ and $\mathrm{Zn}$ in water (W) and interstitial water of sediments (IW) along the Prut River during of 2009 year. Heavy metals mobilization during of sediments re-suspension (ReS) performed in field conditions.

Taking into account the contribution of sediments in the processes of secondary pollution, it was modeled the sediments desorption, i.e. the shaking of the freshly sampled sediments in laboratory conditions (Tab. 1). The quantities of mobilized heavy metals are higher than those recorded in the water layer. The obtained results indicate that for sediments collected in summer there is characteristic a greater mobilization of heavy metals. It was found that due to the sediments desorption the content of $\mathrm{Cu}$ have increased in the water horizon by 2.4 times (summer), $\mathrm{Zn}-$ by 1.3-1.5 times (spring) and by 2.5-3 times (summer).

During spring-summer of 2009 year, the content of Mn in the Prut River water has been identified less than $5 \mu \mathrm{g} / \mathrm{L}$. The obtained results indicate that during of the sediments desorption, the quantity of $\mathrm{Mn}$ have increased in the water layer by 1.6-6.6 times (spring) and 2-8.8 times (summer).

The intense mobility has registered for iron. The mobilized quantities of $\mathrm{Fe}$, during the sediments desorption, 
were by 5-15 times in the spring and by 37-101 times in summer more than data recorded in the water layer of the Prut River.

Spring

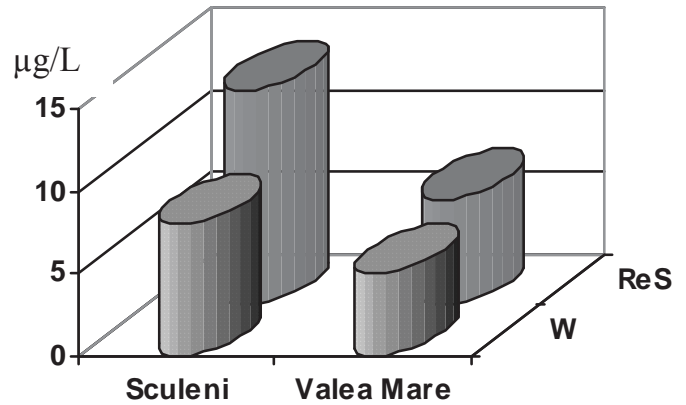

Summer

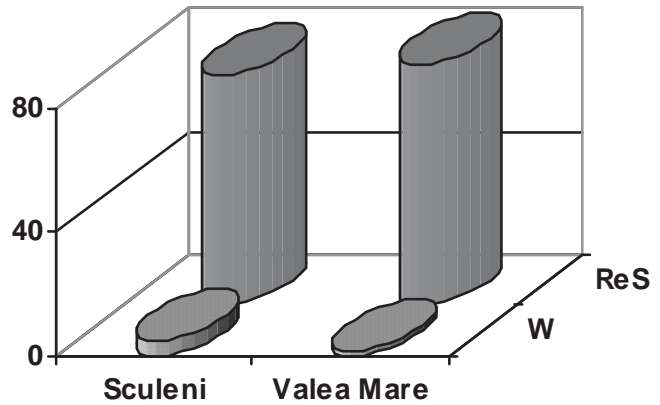

Figure 3. Iron (Fe) mobilization during of sediments re-suspension (ReS) performed in field conditions along the Prut River (2009).

Table 1.

The mobilized metals quantities during desorption from the Prut River sediments during of 2009 year, laboratory modeling

\begin{tabular}{|c|c|c|c|c|c|c|c|c|}
\hline Station & $\mathrm{Cu}, \mu \mathrm{g} / \mathrm{L}$ & $\mathrm{Cu}, \%$ & $\mathrm{Zn}, \mu \mathrm{g} / \mathrm{L}$ & $\mathrm{Zn}, \%$ & $\mathrm{Mn}, \mu \mathrm{g} / \mathrm{L}$ & $\mathrm{Mn}, \%$ & $\mathrm{Fe}, \mu \mathrm{g} / \mathrm{L}$ & $\mathrm{Fe}, \%$ \\
\hline & \multicolumn{8}{|c|}{ Spring } \\
\hline Sculeni & 5 & 1.5 & 14 & 1.6 & 11 & 0.13 & 340 & 0.11 \\
\hline Valea Mare & 3 & 1.7 & 13 & 1.0 & 5 & 0.12 & 650 & 0.44 \\
\hline Cahul & 5.5 & 1.9 & 10 & 1.1 & 33 & 0.38 & 220 & 1.1 \\
\hline \multirow[t]{2}{*}{ Caslita-Prut } & 3 & 1.1 & 15 & 1.7 & 8 & 0.1 & 450 & 0.17 \\
\hline & \multicolumn{8}{|c|}{ Summer } \\
\hline Sculeni & 7.3 & 4.4 & 36 & 7 & 29 & 0.37 & 184 & 0.12 \\
\hline Valea Mare & 12 & 8.7 & 25 & 4.1 & 16 & 0.48 & 202 & 0.2 \\
\hline Giurgiulesti & - & - & 48 & 6.9 & 44 & 0.44 & 1280 & 0.7 \\
\hline
\end{tabular}

\section{Effect of bottom sediments re-suspension on phosphorus dynamics}

Bottom sediments in aquatic system are repositories for various elements, acting both as sinks and sources of supplying for the elements to overlying water column. Once pollutants are discharged into rivers, these chemicals undergo interactive reactions through series of processes including dissolution/precipitation and sedimentation/resuspension, finally settle down in bottom sediments [2].

During turbulent moments (e.g. winds), the bottom sediments are fretted and suspended in water horizon above sediments, i.e. the re-suspension phenomena takes place. Figures 4 and 5 are presenting the content of phosphorus forms (orthophosphates, poly- and pyrophosphates, organic phosphorus) in the water layer, before and after the bottom sediments re-suspension.

In such conditions the content of phosphorus-orthophosphate in the water layer of the Prut River above the sediments can increase by 1.5-3 times, compared with its quantity until the re-suspension (Fig. 4). The obtained data are the same with the information presented for other aquatic objects [9], which identified an increase of phosphorusorthophosphate levels by 1.5-2 times due to the re-suspension of sediments. The content of condensed phosphorus forms (poly- and pyrophosphates) is also increasing by 1.6-2.6 times during the sediments re-suspension, which constitute $28-40 \%$ of its value in the interstitial water. The organic phosphorus is increasing by 1.4-2 times, in comparison with its content until the sediments re-suspension (Fig. 5).

Laboratory modeling of the bottom sediments re-suspension shows that considerable amount of phosphorus is desorbed from the bottom sediments. It was established that during of sediments desorption the content of phosphorus- 
orthophosphate $\left(\mathrm{P}_{-} \mathrm{PO}_{4}\right)$ increased in the water horizon by 2.4-2.8 times (spring) and 1.4-2.3 times (summer) and the quantity of inorganic phosphorus (P-inorg) - by 1.1-2.7 times (Tab. 2).

The intense mobility of phosphorus were recorded during desorption of sediments sampled during of 2011 year (Tab. 3). The mobilized quantities during the sediments desorption were by $\sim 4$ times $\left(\mathrm{P}_{-} \mathrm{PO}_{4}\right)$, by $2.6-5$ times $(\mathrm{P}-\mathrm{inorg})$ and by 3.2-9.5 times (P-org) higher compared to data recorded in the water layer of the Prut River.

Orthophosphates
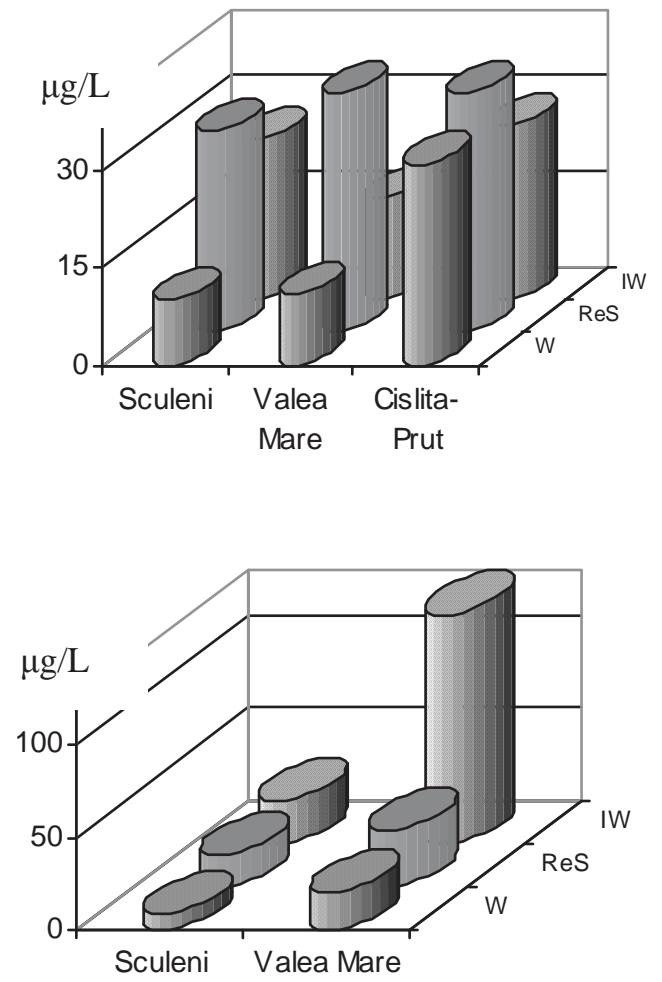

Spring Poly-, pyrophosphates

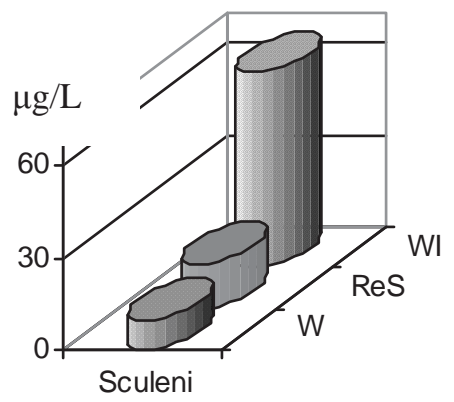

Summer

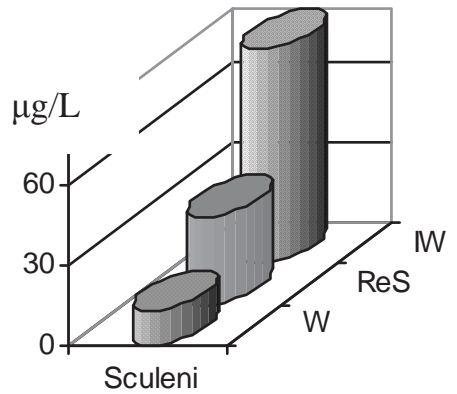

Figure 4. Dynamics of orthophosphates and poly-, pyrophosphates in water (W) and interstitial water of sediments (IW) along the Prut River during of 2009 year. Phosphorus mobilization during the sediments re-suspension (ReS) performed in field conditions.

Spring

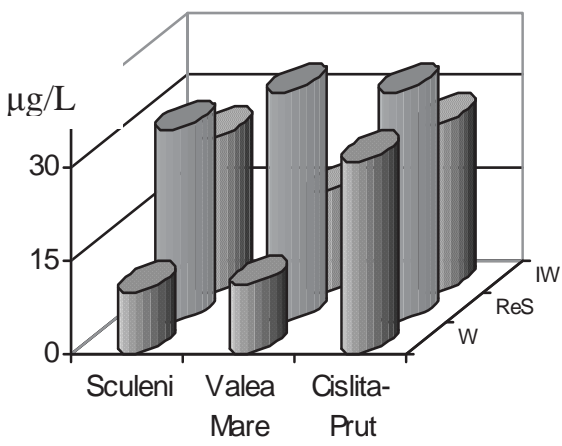

Summer

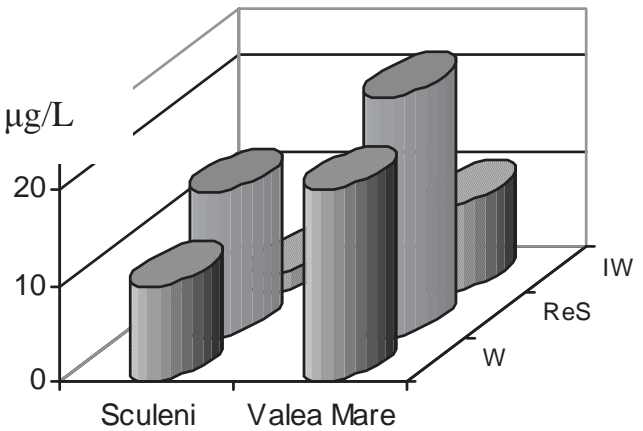

Figure 5. Dynamics of organic phosphorus in water (W) and interstitial water of sediments (IW) along the Prut River during of 2009 year. Phosphorus mobilization during the sediments re-suspension (ReS) performed in field conditions. 
Results presented in the tables 2 and 3 demonstrate that under such conditions about 1.1-16\% from the total quantity of inorganic phosphorus (P-inorg) and about $0.3-24 \%$ from the total quantity of organic phosphorus (P-org) can be desorbed from sediments.

Table 2.

Phosphorus amount desorbed from the bottom sediments of the Prut River during of 2009 year, laboratory modeling.

\begin{tabular}{|c|c|c|c|c|c|}
\hline Station & $\mathrm{P}_{-} \mathrm{PO}_{4}, \mu \mathrm{g} / \mathrm{L}$ & P-inorg, $\mu \mathrm{g} / \mathrm{L}$ & P-inorg, $\%$ & P-org, $\mu \mathrm{g} / \mathrm{L}$ & P-org, $\%$ \\
\hline Sculeni & 23 & 31 & 2.4 & 58 & 69 \\
\hline Valea Mare & 31 & 62 & 5.8 & 30 & 24 \\
\hline Cahul & 25 & 58 & 11 & 65 & 17 \\
\hline Caslita-Prut & 21 & 116 & 16 & 4 & 1.6 \\
\hline \multicolumn{7}{|c|}{ Summer } \\
\hline Cobani & 13 & 30 & 3.6 & 7 & 2.7 \\
\hline Sculeni & 13 & 34 & 4.9 & 3 & 0.8 \\
\hline Valea Mare & 21 & 59 & 15 & 0.3 & 0.3 \\
\hline Giurgiulesti & 18 & 24 & 2.1 & 20 & 17 \\
\hline
\end{tabular}

Table 3.

Phosphorus amount desorbed from the bottom sediments of the Prut River during spring of 2011 year, laboratory modeling.

\begin{tabular}{|c|c|c|c|c|c|}
\hline Station & $\mathrm{P}-\mathrm{PO}_{4}, \mu \mathrm{g} / \mathrm{L}$ & P-inorg, $\mu \mathrm{g} / \mathrm{L}$ & P-inorg, $\%$ & P-org, $\mu \mathrm{g} / \mathrm{L}$ & P-org, $\%$ \\
\hline Ungheni & 38 & 54 & 1.4 & 21 & 2.8 \\
\hline Frasinesti & 23 & 61 & 1.1 & 26 & 2.3 \\
\hline Leova & 34 & 69 & 1.8 & 184 & 17 \\
\hline Branza & 70 & 107 & 2.5 & 92 & 8.6 \\
\hline
\end{tabular}

\section{Conclusions}

The results suggest that during the re-suspension, bottom sediments can become a relevant source of phosphorus forms which are mobilized in the water horizon overlying the bottom sediments.

It was established that during the re-suspension of the Prut River sediments, performed in field conditions, the content of $\mathrm{Cu}$ in the water layer have been increased by 1.5 times, of $\mathrm{Zn}$ - by 1.8-5.7 times and the quantity of Fe - by 1.1-39 times, in comparison with data recorded until the re-suspension. In such conditions, the amount of Cu mobilized in the water layer is $19-52 \%$, of $\mathrm{Zn} 23-100 \%$ and of Fe $7-32 \%$ of their content in the interstitial water, the highest migration mobility being recorded for zinc.

During the sediments re-suspension, in the water layer, the phosphorus-orthophosphate quantity have been increased by 1.5-3 times, the poly-, pyrophosphates - by 1.6-2.6 times and the content of organic phosphorus - by 1.42 times, in comparison with the data recorded until the re-suspension. The highest mobility was registered for organic phosphorus, establishing during the re-suspension the higher values than their content in the interstitial water.

\section{References}

[1] Siepmann, R.; von der Kammer, F.; Calmano, W. Determination of Heavy Metal Mobility from Resuspended Sediments Using Simulated Natural Experimental Conditions, Sediment Dynamics and Pollutant Mobility in Rivers An Interdisciplinary Approach, Westrich B., Forstner U. (Eds.) (C) Springer-Verlag Berlin Heidelberg, 2007, pp. 258-268.

[2] Lee, S.; Moon, J.; Moon, H. Heavy metals in the bed and suspended sediments of Anyang River, Korea: Implications for water quality, Environmental Geochemistry and Health, 2003, 25, pp. 433-452.

[3] Krogerus, K.; Ekholm, P. Phosphorus in settling matter and bottom sediments in lakes loaded by agriculture, Hydrobiologia, 2003, 429, pp. 15-28.

[4] Kowalczewska-Madura, K.; Dondajewska, R.; Goldyn, R. Changes of phosphorus concentration in bottom 
sediments and in overlying water of two strongly eutrophicated lakes in Wielkopolska Region, Limnological Review, 2007, 7(4), pp. 205-211.

[5] Rusu, V.; Lupascu, T. Chemistry of aquatic sediments. Surface properties. Physico-chemical models. Chisinau, 2004. -272 p. (Rom).

[6] Petersen, W.; Willer, E.; Willamowski, C. Remobilization of trace elements from polluted anoxic sediments after resuspension in oxic water, Water, Air and Soil Pollution, 1997, 99, pp. 515-522.

[7] Stigliani, W. Changes in valued "capacities" of soils and sediments as indicators of nonlinear and time-delayed environmental effects, Environmental Monitoring and Assessment, 1988, 10, pp. 245-307.

[8] Madera, V.; Allen, H. E.; Minear, R. A., Eds. Examination of Water for Pollution Control, World Health Organization. Pergamon Press: Copenhagen, Denmark, 1982; 1st Ed., vol. 2; pp. 310-319.

[9] Martynova, M. Re-suspension effects of the bottom sediments on water body ecosystem, Geography and natural resources, 2007, 4, pp. 38-41 (Russ). 